\title{
The Eurosystem's monetary policy following the end of net asset purchases
}

Óscar Arce, Galo Nuño and Carlos Thomas 


\section{Abstract}

This article analyses the monetary policy conduct framework in the euro area following the end of net purchases under the financial asset purchase programme. First, there is a review of the monetary policy measures since 2014 and of the ECB's announcements on the future course of its instruments, comparing the recent changes in euro area monetary policy with the normalisation of US monetary conditions initiated by the Federal Reserve in 2013. Second, the authors analyse the main instruments currently available to the ECB (forward guidance on interest rates and its asset portfolio reinvestment policy), and discuss how both instruments provide monetary stimulus in the current setting.

Keywords: central bank balance sheet, unconventional monetary policy, reinvestments.

JEL codes: E52, E58, E4. 


\section{THE EUROSYSTEM'S MONETARY POLICY FOLLOWING THE END OF NET ASSET PURCHASES}

The authors of this article are Óscar Arce, Galo Nuño and Carlos Thomas of the Directorate General Economics, Statistics and Research.

Introduction

The Eurosystem's monetary policy measures in the period 2014-2018
On 13 December 2018, the European Central Bank (ECB) Governing Council decided to end net purchases of financial assets under its APP (Asset Purchase Programme). At the same time, the Council announced its intention to continue fully reinvesting the principal payments from maturing securities under the Programme for an extended period after the date on which it begins to raise its policy interest rates and, in any event, for as long as necessary to maintain favourable liquidity conditions and an ample degree of monetary accommodation.

The end of net purchases under the APP marks the beginning of a new phase for the Eurosystem's monetary policy. In this phase, forward guidance, accompanied by the reinvestment policy, has become the main monetary policy instrument.

The aim of this article is to analyse the monetary policy conduct framework in this new phase. In this connection, it briefly reviews the Eurosystem's monetary policy since 2014 and the Federal Reserve's experience in normalising its monetary policy, initiated in 2013. Finally, there is a review of the current instruments available to the Eurosystem and an analysis of its capacity to promote the maintenance of easy monetary and financial conditions and to boost inflation in the current economic situation.

Since the onset of the financial crisis in 2007, the ECB and other central banks have complemented their operating frameworks with several unconventional monetary policy tools. Pre-crisis, the ECB's basic instruments were its policy interest rates, through which it sought to control short-term rates on money markets, summarised in indicators such as the EONIA. ${ }^{1}$ This monetary policy signal would be propagated throughout the financial system, influencing a wide range of financial conditions and, finally, macroeconomic dynamics, including consumer prices.

During the financial crisis, this operating framework proved insufficient. This was due to the dislocations in certain segments of the financial system, which hampered the transmission of monetary policy, and to the fact that the duration and scale of the crisis obliged the ECB to lower its deposit facility rate to $0 \%$. The unconventional monetary policy measures introduced by the ECB prior to June 2014 focused chiefly on resolving the first of these problems, i.e. on repairing the monetary policy transmission mechanism. These measures included, for example, the provision of long-term liquidity to the banking sector and asset purchases in market segments that were not operating correctly, through the securities market programme (SMP).

As from June 2014, the ECB gradually introduced a series of measures aimed not only at improving monetary policy transmission but also at bolstering the expansionary stance of monetary policy. It did so against a background of strong easing in the inflation rate, and of its expected medium-term values, accompanied by some slowing in economic growth. The measures spanned three complementary areas: (i) the introduction of negative interest

1 These benchmark interest rates are: the interest rate on the main refinancing operations (MROs), the rate on the deposit facility (DFR) and the rate on the marginal lending facility (MLF). The EONIA (Euro Overnight Index Average) is the main indicator of overnight interbank loan rates in the euro area. 
The ECB has introduced three types of unconventional monetary policy measures since 2014: i) negative interest rates; ii) forward guidance; and iii) the resumed and intensified expansion of the Eurosystem balance sheet.
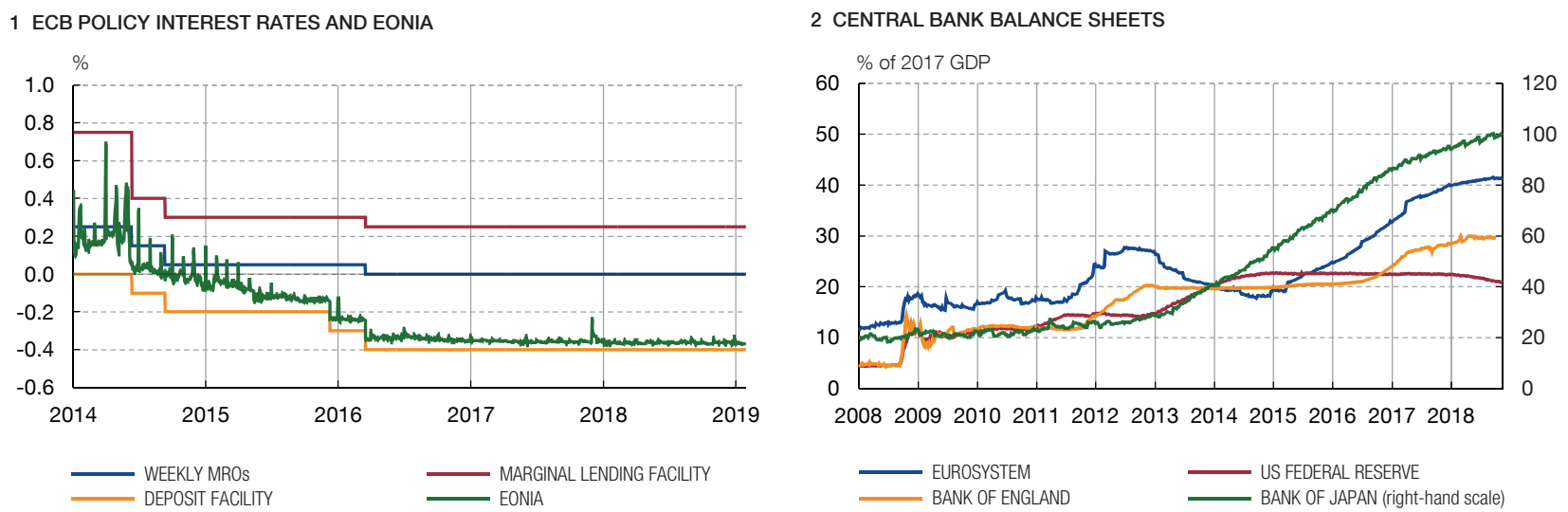

3 ASSET PURCHASE PROGRAMME (APP)

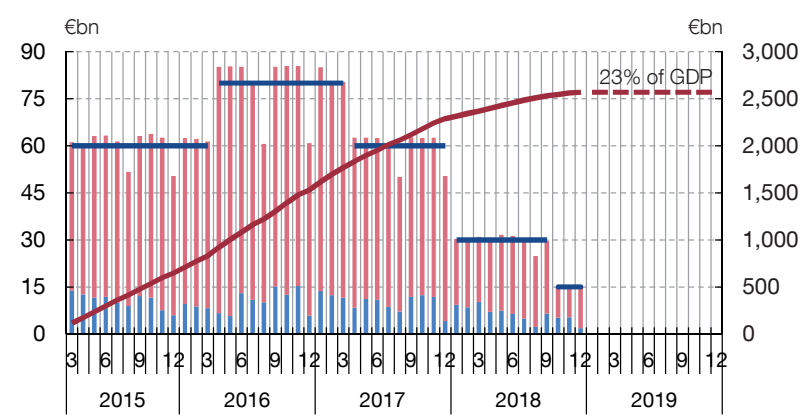

PUBLIC SECURITITES

- MONTHLY NET PURCHASES

\section{PRIVATE SECURITIES}

- - - APP: TOTAL PORTFOLIO (right-hand scale)
4 VALUE OF APP PORTFOLIO AND TLTROs

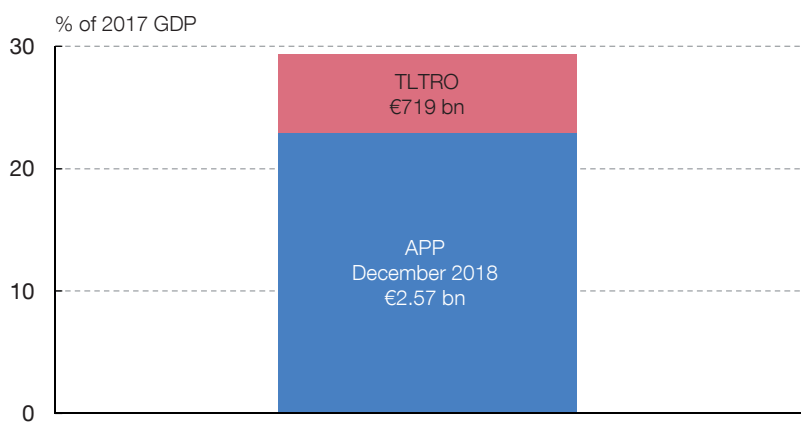

SOURCES: IFS Datastream, ECB and Banco de España.

rates, (ii) communication policy regarding the future course of monetary policy and (iii) the resumption and intensification of the expansion of the Eurosystem balance sheet (see Chart 1).

Firstly, the ECB moved its interest rates into negative territory in June 2014 by placing the deposit facility rate at $-0.10 \%$.

The second facet of the ECB's monetary policy implementation in recent years has been a systematic inclusion in its communication of guidance about the future course of its monetary policy. This instrument has been applied both in the case of conventional and unconventional measures. It has helped emphasise the expansionary stance of monetary policy, providing an additional stimulus by contributing to anchoring agents' expectations about the future course the ECB would follow for its main instruments, reducing the socalled term premia of medium and long-term interest rates. In the case of interest rates, forward guidance initially involved announcing that rates would hold at "current or lower levels" for an "extended period of time". As from March 2016, the ECB linked for the first time the future path of rates to the duration of the APP programme, reinforcing its previous formulation with the expression "and well beyond the horizon of our net purchases". In June 2018, together with the Governing Council foretelling the end of net purchases as 
Following the ECB's announcements, the EONIA yield curve shifted rightwards. That reflects a delay in market expectations about the first rise in rates.

INSTANTANEOUS OIS FORWARD CURVE (a)

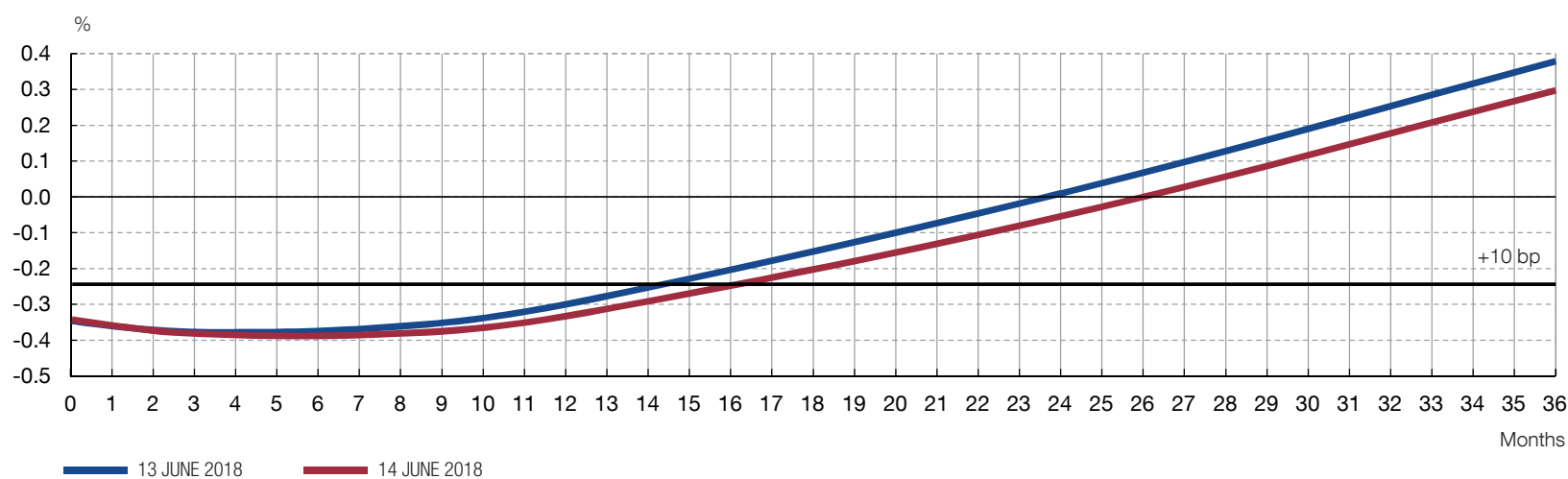

SOURCE: Banco de España.

a The intersection of the " $+10 \mathrm{bp}$ " horizontal line (i.e. EONIA as at 14 June 2018 plus $10 \mathrm{bp}$ ) with the OIS curve at each reference date may be interpreted as the market's estimation of the future time (in months, as from the reference date) at which the first rise in the DFR from its current level is expected. This is under the dual assumption that this rise: i) will be $10 \mathrm{bp}$, and ii) will cause an increase by the same amount in the EONIA indicator that acts as a reference for OIS contracts. According to the chart, the Governing Council's announcement on 14 June 2018 delayed the expected time of the first rise in the DFR by approximately 2 months.

Download

from December that year, a release was launched for the first time on future interest rates linked to a specific time (approximately), with the announcement of its expectation that there would be no rate rises "at least through the summer of 2019 ". $^{2}$ This element of forward guidance, which when introduced managed to put back the expected moment for the first rise in interest rates (see Chart 2), has generally proven effective when setting agents' expectations about the minimum horizon in which such a rise may take place. ${ }^{3}$

Thirdly, in June 2014 the ECB introduced the targeted long-term refinancing operations (TLTROs, reintroduced in the March 2016 Council as TLTRO-II). These operations acknowledged the importance of bank intermediation in the euro area, enabling institutions to fund themselves long-term - with maturities of up to 4 years - under conditions that were favourable but linked to lending granted to the non-financial private sector performing dynamically. Moreover, the ECB decided in January 2015 to introduce an expanded asset purchase programme with a view to impacting overall euro area financial conditions more directly. ${ }^{4}$

The APP programme was activated in March 2015 with public and private bond purchases for a total value of $€ 60$ billion per month over an initial time horizon running to September 2016. Given the need to prolong the monetary stimulus, the programme was recalibrated

2 This time reference was supplemented as follows: "and in any case for as long as necessary to ensure that the evolution of inflation remains aligned with the current expectations of a sustained adjustment path". With slight changes, this formulation has been maintained following subsequent Governing Council meetings.

3 The OIS (Overnight Indexed Swap) curve is shaped by the price of swap derivatives based on the future course of the EONIA at different future horizons. The instantaneous OIS forward curve reflects the EONIA interest rates that should arise at each future moment for which the swaps do not entail a payment from one party to the other. This curve reflects both expectations about the future level of the EONIA rate and the term premium at different horizons. Therefore, this curve is an approximate estimate of the future level of the EONIA.

4 In late 2014 the ECB had already introduced asset-backed securities and covered bond purchase programmes (ABSPP y CBPP3, under which the ECB purchases securitisations and collateralised bonds, respectively), but on a far lesser scale than the public securities purchase programme (PSPP). 
The US Federal Reserve's experience

on several occasions. Some changes extended beyond the time the programme was in force. These altered the size of monthly purchases (which reached up to $€ 80$ billion) and extended the range of eligible assets (including, for example, corporate bonds under the CSPP programme, introduced in June 2016). From April 2017, purchases were reduced to $€ 60$ billion, subsequently declining to $€ 30$ billion in January 2018 and $€ 15$ billion in October later that year. Finally, in December 2018, the Governing Council confirmed the end of net purchases, previously anticipated in June that year (subject to a favourably trending inflation outlook). Overall, the monetary stimulus generated via the TLTROs and the APP was on a sizable scale, which entailed a far-reaching change both in the size and composition of the Eurosystem balance sheet. ${ }^{5}$

Given that the unconventional monetary policy measures applied in recent years by the ECB are new, finding precedents on how the monetary policy normalisation process might unfold in the euro area is not straightforward. Admittedly, the Governing Council has provided some guidance (described at the start of the article) on the potential duration of investments and their link to the beginning of the rise in interest rates; but the strategy for any ECB monetary policy normalisation may only evolve in the future insofar as the sustained adjustment of inflation towards rates compatible with the medium-term stability reference for prices (annual rate of inflation lower than, but close to, $2 \%$ ) actually materialises. Against this background, it is worth analysing the experience of other central banks that are further ahead in their monetary policy normalisation process.

The most significant case in this respect is that of the United States Federal Reserve. From 2008 to 2014, the Federal Reserve pursued a series of public and private asset purchase programmes (see Chart 3). In May 2013, it announced a reduction in the pace of purchases under those programmes still operating. This reduction began in January 2014, and continued until, in October that same year, the end of net purchases and a phase involving the full reinvestment of proceeds from maturing securities were reached, i.e. a similar situation to that of December 2018 in the euro area.

In September 2014, i.e. a month before the end of net purchases, the Federal Reserve announced a review of the principles of its monetary normalisation strategy. According to these principles, normalisation should take the form of rises in the short-term interest rate and a gradual and predictable reduction in the reinvestment of assets. As in the case of the euro area, the reduction in reinvestments would come about after the start of interest rate rises, and the time of that reduction would be determined by the path of economic and financial conditions.

The first interest rate rise in the United States finally came about in December 2015, more than one year after the discontinuation of net asset purchases. Thereafter, there were progressive rises in interest rates, up to the current band of $2.25-2.5 \%$.

As regards the Federal Reserve balance sheet, the full reinvestment of assets purchased under the various quantitative easing programmes was maintained during the first phase of interest rate rises. In June 2017, the Federal Reserve announced that it expected to begin the reduction in reinvestments that same year, provided that the economy generally

5 Mouabbi and Sahuc (2016), for example, calculate an average effect of the APP and TLTRO programmes of $0.25 \%$ on prices and $0.56 \%$ on GDP between 2014 and 2016. Hutchinson and Smets (2017) estimate a cumulative impact of $0.5 \%$ on prices and $1.7 \%$ on GDP between 2016 and 2019. Banco de España (2016) estimates a cumulative impact of $1.2 \%$ on prices and $1.4 \%$ on GDP in the period $2015-2016$. 
From 2008 onwards the Federal Reserve introduced a series of asset purchase programmes that led the size of its balance sheet to increase. After holding it constant from October 2014 to October 2017, it has initiated a progressive balance sheet reduction path.

\section{BREAKDOWN OF FEDERAL RESERVE ASSETS}

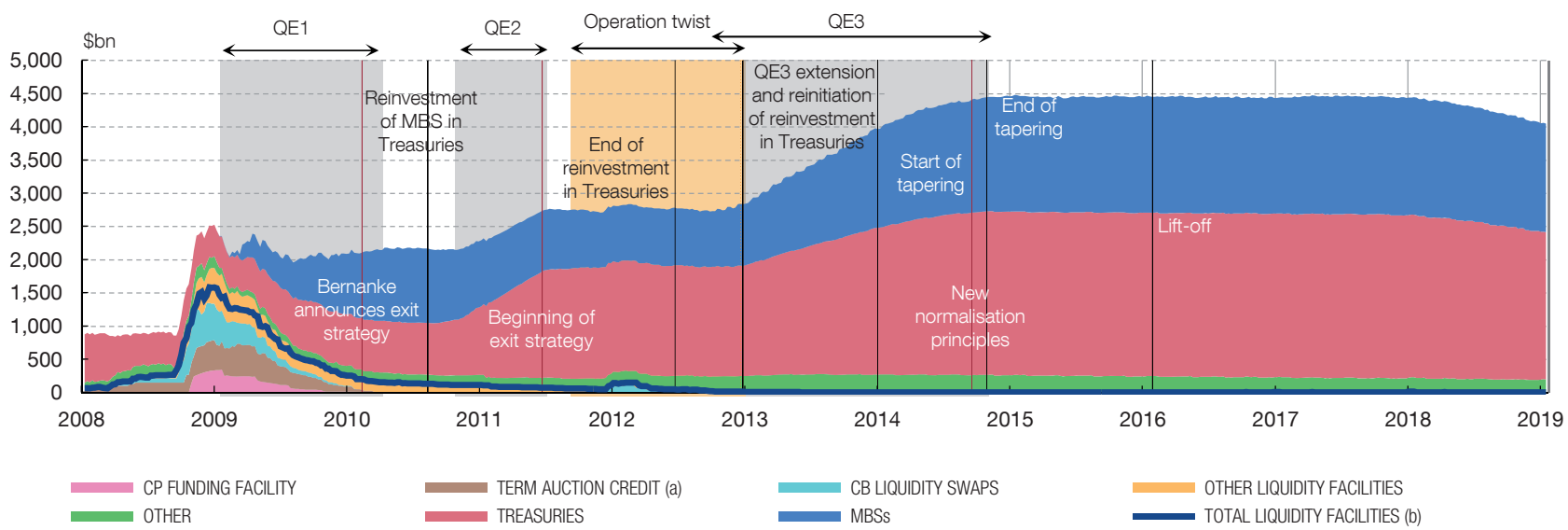

SOURCE: Federal Reserve.

a Credit facility relating to the TAF (Term Auction Facility) programme.

b Includes: Term Auction Credit; Primary Credit; Secondary Credit; Seasonal Credit; Primary Dealer Credit Facility; Asset-Backed Commercial Paper Money Market Mutual Fund Liquidity Facility; Term Asset-Backed Securities Loan Facility; Commercial Paper Funding Facility; unpaid principal on loans to American International Group, Maiden Lane LLC, Maiden Lane II LLC, and Maiden Lane III LLC; and Central Bank Liquidity Swaps.

Download

The ECB's monetary policy instruments in the current phase fared as had been forecast. The start of the balance sheet trimming was finally announced in September 2017, and began in October that year through the non-reinvestment of a portion of its maturing instruments, without specifying the completion date for this process or the objective size of the balance sheet in the long run. The Federal Reserve announced the possibility of resuming full reinvestment principal payments, and of altering the size and composition of the balance sheet if future economic conditions were to warrant a more accommodative policy.

In short, the sequence announced by the ECB Governing Council concerning the adjustment of interest rates and of reinvestments is similar, so far, to the strategy pursued by the Federal Reserve in the initial stages of its monetary normalisation process.

As earlier discussed, the euro area's monetary policy began to be tempered as the risks of a sharp and persistent deanchoring of medium and long-term inflation expectations eased. Initially, the ECB set about gradually reducing net asset purchases, until they stopped at end-2018. Since then, the ECB has switched the main element of its forward guidance from net purchases under the APP towards the future path of interest rates, to which the asset reinvestment policy must be added as a further instrument. By means of the use of both tools, the Eurosystem is in a position to provide broad-based monetary stimulus to euro area financial conditions and inflation, if necessary.

In the case of interest rates, as previously indicated the ECB foresees holding them at their current levels "at least through the summer of 2019" and in any case for as long as necessary to ensure that the evolution of inflation remains aligned with the current expectations of a sustained adjustment path. This leaves the door open to changes that strengthen, where necessary, the positive effects on financial conditions. On one hand, 
communication should be reinforced about the time at which the first rise in interest rates from their current levels (the so-called lift-off) should come about, either by delaying the future date before which such a rise would not be expected, in what has been called "calendar-based" guidance, or by linking this rise to actual inflation (or expected inflation, at a specific but not excessively distant horizon) reaching or exceeding a specific level, i.e. "state-contingent" guidance. ${ }^{6}$ On the other hand, it would be possible to offer guidance on the pace of subsequent interest rate rises, with the possibility of once again linking this pace to macroeconomic developments. ${ }^{7}$

In the case of full asset portfolio reinvestment, the December 2018 ECB Governing Council announced its intention to maintain this policy "for an extended period of time" following any initial rise in interest rates, in a link between both tools that has been called chained forward guidance. Once again, this formulation offers variations that might strengthen, where necessary, the stimulus effect of reinvestments. Firstly, there would be a possibility of specifying the precise meaning of "extended period of time" by setting a minimum duration of the reinvestment as from the first rise in rates; ${ }^{8}$ that would be a "quantitative" version of the above-mentioned chained forward guidance. ${ }^{9}$. Secondly, it would be possible to announce changes in the composition of reinvestments in terms of residual maturity, with a view to increasing the degree of absorption of maturity risk by the programme and, therefore, the accommodative impact on the longer-dated segments of the yield curves. Further ahead, two possible options for reinforcing the positive effect of the reinvestments would be to specify both the pace of reduction of reinvestments once they ceased to be full and the duration of the ongoing shrinkage of the programme's portfolio. In combination, both elements would offer information on the size of the Eurosystem's balance sheet in the long term.

Beyond the qualitative arguments set out, it is worth quantifying, albeit tentatively, the possible macroeconomic effects of forward guidance on the path of interest rates and on asset reinvestments. Box 1 conducts a quantitative exercise, drawing on the dynamic general equilibrium model in Arce, Hurtado and Thomas (2016). The analysis suggests that both tools are potentially useful for stimulating economic activity and inflation in the euro area, especially when the announcements on the duration of reinvestments are accompanied by others on the future path of interest rates designed to boost the expansionary effect of reinvestments. ${ }^{10}$

In sum, the end of the ECB's net asset purchases has ushered in a new phase in which forward guidance on interest rates and the reinvestment of proceeds from maturing assets have taken on the role of the main monetary stimulus tools. Both tools allow for changes

6 By way of example, in December 2012, the Federal Reserve used state-contingent guidance, announcing that it did not envisage raising interest rates while unemployment held above $6.5 \%$ and inflation and the attendant expectations remained stable.

7 This possibility is discussed, for example, in Coeuré (2018).

8 Naturally, this hypothetical change in communication would only entail further stimulus insofar as there were a lengthening of the reinvestment horizon in financial markets' expectations.

9 It would in principle also be possible to add state-contingent elements in the duration of investments, e.g. linking such duration to the course of inflation. However, the fact that communication of the lift-off of interest rates is already linked to the adjustment of inflation, along with the binding linkage of the reinvestment horizon to the time of such lift-off, means that a change of this nature would be somewhat redundant. In the future, once there is a rise in rates (or its date is specified), it would indeed be useful to link the reinvestment horizon to the path of inflation.

10 Specifically, the box considers a variation of forward guidance under which the central bank, at the time of announcing a specific duration of reinvestments, also commits to not bringing forward the time of the first rise in rates and to not accelerating the subsequent pace of rises as a result of the potential expansionary effect of the reinvestments on real activity and inflation. 
in their formulation aimed at strengthening this stimulus where necessary, for example in the event of a severe reversal in the trajectory of recovery of the economy and euro area inflation; indeed, it is possible to introduce other additional measures, as repeatedly asserted by various senior Eurosystem officials. ${ }^{11}$

21.2.2019.

\section{REFERENCES}

ALTAVILLA, C., G. CARBONI and R. MOTTO (2015). "Asset purchase programmes and financial markets: lessons from the euro area". Working Paper Series 1864, European Central Bank.

ARCE, O., S. HURTADO and C. THOMAS (2016). "Policy Spillovers and Synergies in a Monetary Union". International Journal of Central Banking, 12(3), 219-277.

BANCO DE ESPAÑA (2016). Chapter 3 "The effect of the ECB's monetary policies in the recent period". In Annual Report 2015, Madrid, Banco de España.

CHEN, H., V. CÚRDIA and A. FERRERO (2012). "The Macroeconomic Effects of Large-scale Asset Purchase Programmes". Economic Journal, 122(564), 289-315.

COEURÉ, B. (2018). "Forward guidance and policy normalization". Address before the Deutsches Institut für Wirtschaftsforschung, 17 September.

- (2019). Interview with Barron's conducted by Pierre Briançon on 5 February 2019.

DRAGHI, M. (2018). "Central Bank Independence", First Lamfalussy Lecture at the Banque Nationale de Belgique, Brussels, 28 October 2018.

- (2019). "Debate of the European Parliament about ECB's annual report 2017", Strasbourg, 15 January 2019.

HUTCHINSON, J., and F. SMETS (2017). "Monetary Policy in Uncertain Times: ECB Monetary Policy Since June 2014." The Manchester School 85, pp. e1-e15.

MOUABBI, S., and J.-G. SAHUC (2016). "Evaluating the Macroeconomic Effects of the ECB's Unconventional Monetary Policies." Working Paper, Banque de France.

11 See, for instance, Draghi (2019) ("Faced with unprecedented threats to price stability, the ECB adapted its policy instruments to continue delivering on its mandate. We will continue to do so if and when needed..."), Draghi (2018) ("Faced with future crises, central banks will adhere to their mandates and use their independence to fulfil them. In our case, the ruling of the European Court of Justice has shown that we can use all the tools within our mandate to tackle future challenges to price stability. We cannot foresee now what those challenges might be, but if and when they arise, they may require us to adjust our policy space once more to meet our mandate."), and Coeuré (2018) ("We are now well equipped to face many different types of situations (...) And we even have instruments that were announced but have never been used. But even with all this, if we were facing new situations in the future, I'm confident we could be creative again and come up with efficient instruments, all within our legal mandate.") 
The aim of this box is to illustrate, in the context of a macroeconomic model, the effectiveness of the two main tools currently available to the ECB following the end of its net asset purchases: reinvestments and forward guidance on interest rates. In this connection, an analysis based on the dynamic general equilibrium model in Arce, Hurtado y Thomas (2016) is conducted. This model considers a monetary union with two blocks, respectively encompassing the "core" and the "peripheral" countries. In the model, the central bank can purchase long-term public debt as part of its "unconventional" monetary policy arsenal. ${ }^{1}$

The simulation exercise seeks to approach the current situation in the euro area by considering a negative shock that has prompted a severe enough recession for the short-term interest rate to have reached its lower bound. Against this background, the central bank implements a bond purchase programme (similar to the APP) for several quarters. Following the end of net purchases the interest rate holds at its lower bound, but its adjustment is expected to start after a few quarters. In this setting, an analysis is made of the effects of different announcements relating to the reinvestments horizon and the possible interaction with further announcements on the future path of interest rates. ${ }^{2}$

The middle panel of Chart 4 shows the dynamic impact on the monetary union's aggregate GDP of announcing different reinvestment horizons, relative to the path of GDP in the case in which it is announced that there will be no reinvestments at the end of net purchases. In all instances, the impact is concentrated chiefly in the quarter in which the announcement is made.

The top panels in the chart show the impact on GDP and inflation at different horizons: (i) at the time of the announcement; (ii) the first year; and (iii) the first five years. For both variables the marginal effect of extending the reinvestment horizon tends to diminish

1 These purchases have real effects owing to the existence of a segmentation in households similar to that considered in Chen, Cúrdia and Ferrero (2012). Hence, a fraction of households can only save in long-term public debt, while other households can also invest in shortterm debt, but they face adjustment costs if the composition of their portfolios diverges to some degree. A key parameter in the model is the elasticity of these adjustment costs. This parameter is calibrated to replicate the empirical results in Altavilla, Carboni and Motto (2015) on the response of long-term German and French sovereign debt yields to the announcement of the APP programme. This calibration is deliberately cautious, since the same empirical results encountered appreciably higher responses by the sovereign yields of other countries such as Spain and Italy to the APP announcement.

2 Following the announcement of the end of reinvestments, central bank bond holdings have diminished as such bonds progressively mature. over time. The reason is that, when the reinvestment horizon is short, the beneficial effects of the absorption of bonds by the central bank largely coincide with the period in which the nominal interest rate remains anchored at its lower bound; therefore, the conventional monetary policy does not undo - through an earlier and/or swifter normalisation path - the expansionary effects of the reinvestments on inflation and activity. ${ }^{3}$ However, when the reinvestment horizon extends beyond that period, prolonging reinvestments over more years is offset by the endogenous tightening of monetary policy; that is to say, the rise in rates induced by the increase in inflation and in GDP prompted by asset reinvestments.

One means of countering this loss in efficiency of reinvestment announcements is by combining them with guidance on the future path of interest rates. For example, take the instance where the central bank points to a rate normalisation path - in response to a progressive improvement in the macroeconomic situation - that is more gradual than what it would follow under normal conditions, such that it does not neutralise the expansionary effects of reinvestments with swifter rate rises. To formalise this notion in the model, we consider an alternative scenario under which the central bank undertakes to follow, for a short period after the start of the rate rises, the same interest rate path as in the scenario without reinvestments. Accordingly, this exercise enables the combined effect of reinvestments and forward guidance on interest rates to be quantified.

The lower panels of Chart 4 show how the impact of the various reinvestment announcements under this alternative scenario is clearly more acute. For example, for the longer reinvestment horizons, the effect at the time of the announcement on GDP and inflation is $0.6 \%$ and $0.5 \%$, respectively, compared with $0.2 \%$ for both variables in the case without forward guidance (top panels).

This latter exercise therefore illustrates the need for the central bank to calibrate communication of the future path of interest rates and the asset reinvestment policy; the central bank must be mindful of the interactions between both these unconventional monetary policy instruments. The need for this overview is particularly pertinent in the current context of the Eurosystem where, as this article explains, communication of these two variables comprises the core of the monetary instruments the ECB currently uses.

3 In the model, conventional monetary policy follows the so-called "Taylor rule", which links the short-term interest rate to the monetary union's inflation and real activity. 
Chart 1

EFFECTS OF REINVESTMENTS FOR DIFFERENT TIME HORIZONS (a)

Effects on euro area GDP and inflation of different reinvestment horizons, considering cases with/without guidance on interest rates following the first rise.

\section{EFFECTS OF REINVESTMENTS FOR DIFFERENT HORIZONS.} EURO AREA GDP

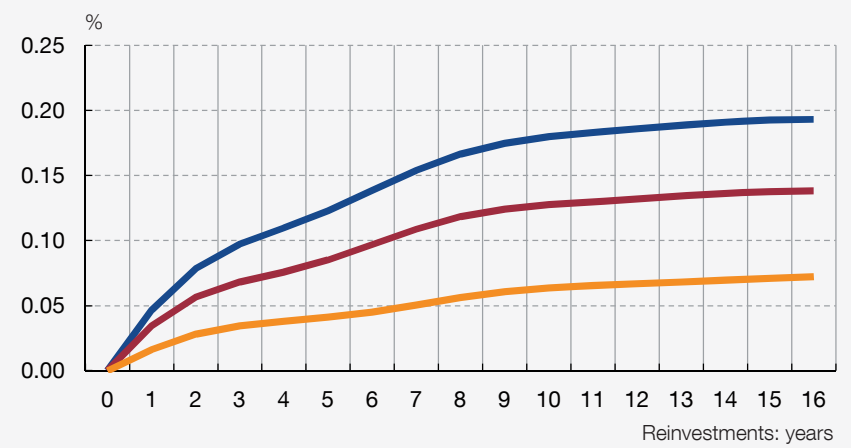

\section{EFFECTS OF REINVESTMENTS FOR DIFFERENT HORIZONS.} EURO AREA INFLATION

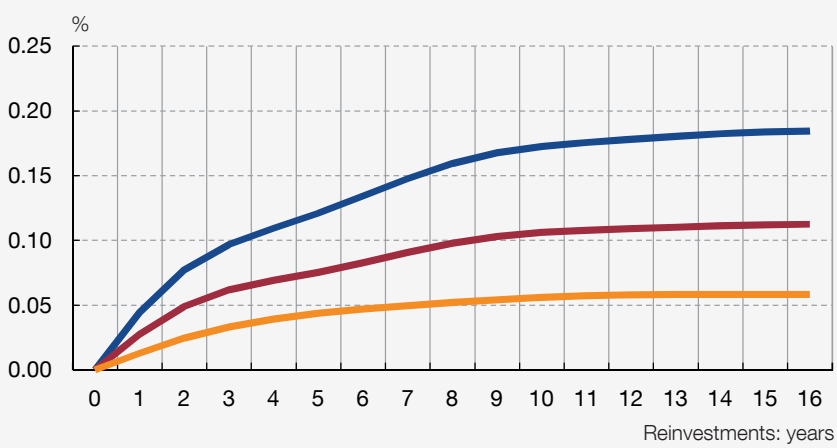

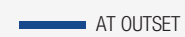

- AT 1 YeAR

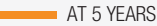

3 EURO AREA GDP

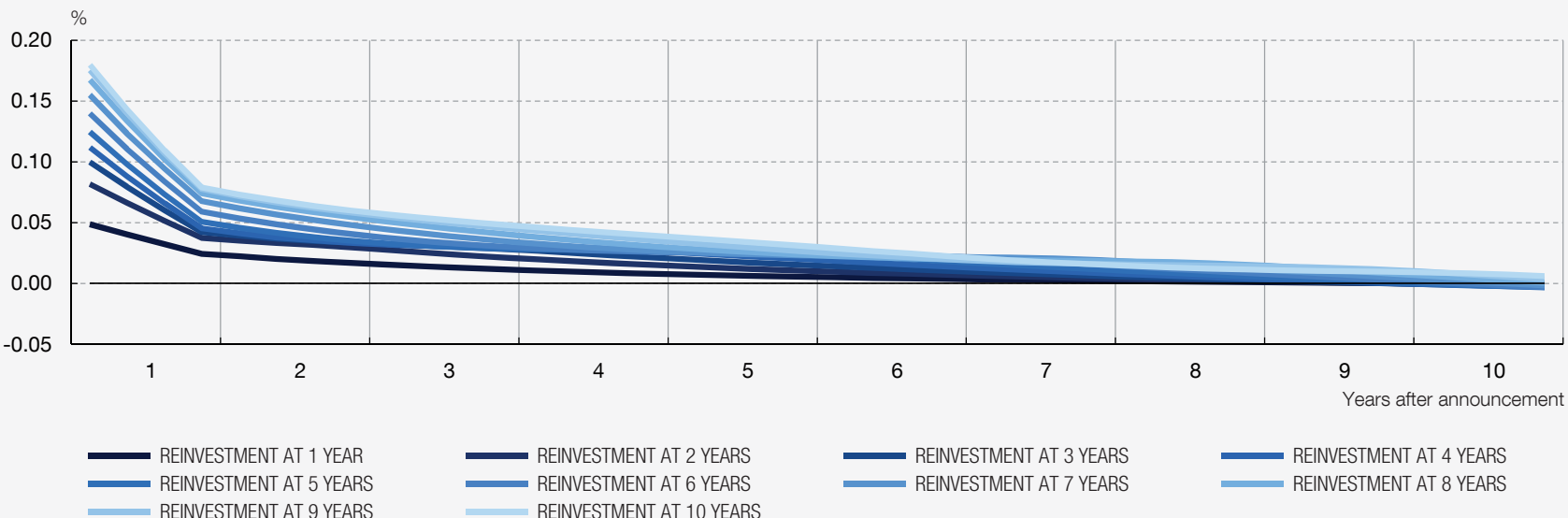

4 EFFECTS OF REINVESTMENTS COMBINED WITH FORWARD GUIDANCE. EURO AREA GDP

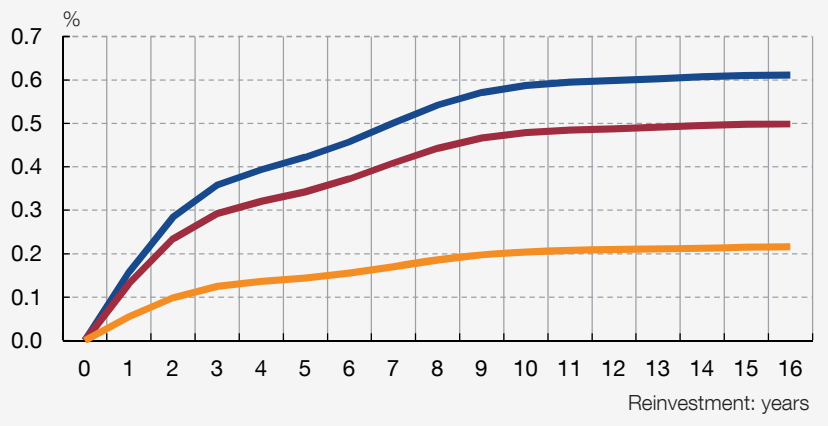

5 EFFECTS OF REINVESTMENTS COMBINED WITH FORWARD GUIDANCE. EURO AREA INFLATION

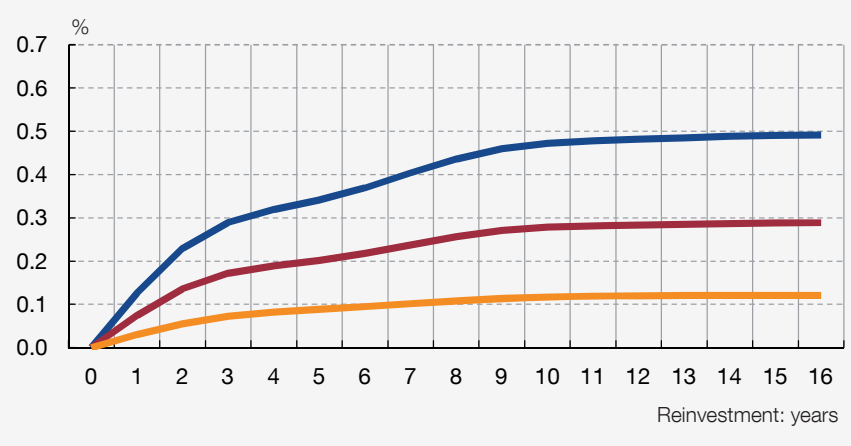

SOURCES: ECB and Banco de España.

a Simulations based on the model in Arce, Hurtado and Thomas (2016). 